\title{
Rio de Janeiro: considerações sobre os processos de expansão urbana e interiorização do crescimento (1980-2010)
}

\author{
Rio de Janeiro: Considerations on the Process of Urban Expansion and \\ Internalization of Growth (1980-2010)
}

Joseane de Souza, José Victor de Paula Frưuozo

Universidade Estadual do Norte Fluminense - Darcy Ribeiro (UENF), Campos dos Goytacazes, RJ, Brasil

\section{Resumo}

Este artigo tem como objetivo analisar o processo de expansão urbana do Estado do Rio de Janeiro, buscando compreender o sentido da interiorização do crescimento populacional no Estado no período de 1980 a 2010. Nesta análise, deu-se ênfase aos movimentos migratórios internos, tendo em vista o seu papel determinante nesse processo. Assim, discutem-se a mudança do papel exercido pelo Estado do Rio de Janeiro, no contexto das migrações internas no Brasil, e a perda da importância das migrações interestaduais enquanto determinantes das áreas de expansão urbana e de interiorização do crescimento. Adicionalmente, demonstra-se o aumento da importância das migrações intraestaduais para tais processos. Por meio dos principais indicadores (consolidados) das migrações internas e das taxas de crescimento populacional médio anual, verificou-se que, pelo menos desde a década de 1980, os municípios do litoral Norte Fluminense - Baixadas Litorâneas e Norte Fluminense - são os que apresentam os maiores saldos migratórios positivos, as maiores Taxas Líquidas de Migração (TLM) e as maiores taxas de crescimento populacional, o que os coloca como a principal frente de interiorização do Estado, ressaltando-se que se faz referência a um processo ainda tímido de interiorização do crescimento, dada a enorme concentração populacional estadual na Região Metropolitana do Rio de Janeiro.

Palavras-chave: Expansão urbana. Interiorização do crescimento. Migrações internas.

\section{Abstract}

This article aims to analyze the process of urban expansion of the State of Rio de Janeiro that took place from the 1980s to the 2010s, trying to understand the meaning of internalization of population growth in the state. In this analysis, we place emphasis on internal migration, considering its key role in this process. In this sense, the study discusses the change in the role played by the State of Rio de Janeiro in the context of internal migrations in Brazil and the loss of importance of interstate migration as determinant of the expansion of urban areas and internalization of growth. In addition, this article demonstrates the increasing importance of intrastate migration to such processes. The key (consolidated) indicators of internal migration and the mean annual rates of population growth showed that since around the early 1980s, the municipalities along the northern coast of Rio de Janeiro - Coastal Lowlands and North of Rio de Janeiro - have been the ones with the greatest

JS: Demografia, Doutorado, e-mail: joseanedesouza.souza@gmail.com

JVPF: Administração Pública, Graduação, e-mail: josevictorfrutuozo@yahoo.com.br

urbe. Revista Brasileira de Gestão Urbana (Brazilian Journal of Urban Management), 2018 jan./abr., 10(1), 124-139 
positive net migration, the largest TLM and the highest rates of population growth. These migration flows represent, therefore, the main front of internalization of the State. It is important to note that these migrations consist of as till timid process of internalization of growth, given the huge concentration of the population in the metropolitan area of Rio de Janeiro.

Keywords: Urban expansion. Internalization of growth. Internal migration.

\section{Introdução}

A expansão urbana brasileira é um fenômeno bastante recente e se relaciona a "um conjunto de mudanças estruturais na economia e na sociedade brasileira a partir da década de 30 do século 20" (Brito \& Souza, 2005, p. 48).

Se, no início, esse fenômeno esteve associado, principalmente, às migrações internacionais, inclusive financiadas pelo próprio Estado brasileiro, a partir da segunda metade da década de 1950, quando houve uma aceleração no processo de industrialização da economia brasileira e, paralelamente, a expansão dos sistemas de transporte e dos meios de comunicação de massa (como condições sinequa non para o próprio desenvolvimento do setor industrial), as migrações internas - interestaduais e intraestaduais tornaram-se cruciais nesse processo. Nas palavras de Brito \& Souza (2005, p. 49), "a migração interna em geral - e não só a rural-urbana - constituiu um dos elos mais importantes entre as profundas mudanças estruturais e a grande transformação urbana".

Os movimentos migratórios foram tão intensos, que o Censo de 1970 (IBGE, 1970) revelou, pela primeira vez, uma população urbana superior à rural - ressaltando-se que esse processo de urbanização ocorreu em velocidade surpreendente, muito superior à dos países capitalistas mais avançados (Brito \& Souza, 2005, p. 49).

A partir da década de 1980 - momento em que a desconcentração industrial iniciada no final da década de 1960 se refletiu com maior ênfase na configuração urbana do país - , o processo de expansão urbana brasileira vem assumindo novas características, tais como: a redução do ritmo de crescimento populacional dos núcleos e das periferias metropolitanas; a aceleração do ritmo de crescimento das cidades pequenas e médias; o aumento dos fluxos pendulares; e a emergência de novos arranjos espaciais da rede urbana brasileira, como as novas aglomerações urbanas não metropolitanas.
Este artigo tem como objetivo analisar o processo de expansão urbana do Estado do Rio de Janeiro no período 1980-2010, buscando-se identificar, na atualidade, qual sua principal direção, com base em informações sobre as migrações internas (interestaduais e intraestaduais).

0 artigo encontra-se dividido em seis seções, além desta primeira, que é a Introdução. Na segunda, apresentam-se os materiais e métodos utilizados para o desenvolvimento das seções subsequentes. $\mathrm{Na}$ terceira, analisa(m)-se, a partir de informações sobre as migrações interestaduais, a(s) mudança(s) de papel(éis) exercido(s) pelo Rio de Janeiro no contexto da expansão urbana brasileira, no período 1872-2010. Na quarta, reconhecendo o papel cada vez maior das migrações de curta distância na definição dos eixos de expansão urbana, analisam-se as migrações intraestaduais no Estado do Rio de Janeiro, buscando-se detectar as principais áreas de atração de expulsão populacional e, consequentemente, a direção da expansão Urbana. Na quinta, analisam-se, a partir dos indicadores consolidados das migrações intraestaduais e interestaduais e das taxas de crescimento populacional, os principais eixos de expansão urbana do Estado do Rio de Janeiro nas últimas décadas. Na sexta, apresentam-se as considerações finais.

\section{Materiais e métodos}

Para compreender o papel do Estado do Rio de Janeiro no contexto das migrações internas no Brasil, no período 1872-1970, lançou-se mão de um clássico estudo desenvolvido por Graham \& Holanda (1980), no qual os autores analisam as migrações internas no Brasil por meio da Razão de Sobrevivência Global (tomada como proxy das Relações Intercensitárias de Sobrevivência), tendo em vista a escassez de informações diretas sobre os movimentos migratórios internos nos Censos Demográficos mais antigos. 
Ainda com o mesmo objetivo, utilizou-se o artigo de Brito (2002), no qual o autor analisa as migrações internas no Brasil no período de 1940-1980. Complementarmente, no âmbito desta pesquisa, foram utilizadas, tal como em Brito (2002) ${ }^{1}$, informações diretas referentes às migrações de última etapa para o período de 19802010, nos Censos de 1991, 2000 e 2010 (IBGE, 1991, 2000,2010 ). Ainda no âmbito desta pesquisa, utilizando esses mesmos Censos analisou-se, na terceira seção, o destino dos imigrantes interestaduais no Estado do Rio de Janeiro, nas últimas décadas, segundo a microrregião e a mesorregião.

As migrações intraestaduais, abordadas na quarta seção, foram analisadas somente para o período mais recente, abrangido por esta pesquisa, qual seja, 1991-2010. Foram utilizadas apenas as informações dos Censos Demográficos de 1991 e 2010, uma vez que, no Censo de 2000, suprimiu-se a informação referente ao nome do município de residência anterior, o que impede a estimativa dos fluxos migratórios de última etapa em nível municipal.

Para os decênios 1981-1991 e 2000-2010, foram confeccionadas matrizes origem-destino por meio do cruzamento das variáveis "Nome do município de residência anterior" e "Nome do município de residência atual", tendo-se o cuidado de selecionar apenas os movimentos restritos ao Estado do Rio de Janeiro. Muito embora se tenha trabalhado com o município, para efeitos analíticos os resultados foram apresentados, assim como no caso das migrações interestaduais, segundo a microrregião e a mesorregião.

Na quinta seção, o objetivo principal foi identificar os principais eixos de expansão urbana do Estado do Rio de Janeiro nas últimas décadas. A limitação do estudo das migrações intraestaduais aos períodos de 1981-1991 e de 2000-2010 implica que estes também serão considerados para esta análise.

Para se identificarem as principais áreas de expansão urbana do Estado do Rio de Janeiro nos períodos de 1981-1991 e de 2000-2010, foram consolidados os dados dos movimentos migratórios interestaduais e intraestaduais, assim como foram estimados o saldo migratório total e a taxa líquida de migração

\footnotetext{
${ }^{1}$ Aplicou-se a mesma metodologia adotada por Brito (2002) migrações de última etapa - de forma a garantir a comparabilidade entre os resultados apresentados nesta pesquisa e os obtidos pelo autor - comparação esta imprescindível para o alcance do objetivo proposto com o desenvolvimento da terceira seção.
}

por município fluminense. Além desses indicadores, estimaram-se também as taxas de crescimento médio anual, segundo a situação do domicílio. Para facilitar as comparações e permitir a identificação espacial das áreas de expansão, esses resultados serão apresentados por meio de mapas temáticos, de elaboração própria com uso do MAPinfo.

Para a confecção dos mapas temáticos referentes ao período de 1981-1991, foi utilizada, por razões de ordem metodológica, a divisão territorial fluminense de 1980, enquanto para os mapas temáticos referentes ao período de 2000-2010, a divisão territorial de 2000 , que apresenta um número significativamente maior de municípios, tendo em vista as emancipações ocorridas ao longo destes 30 anos $^{2}$.

\section{O Rio de Janeiro no contexto das migrações internas}

Segundo Graham \& Holanda (1980), durante o período de 1900-1970, o Estado do Rio de Janeiro se destacou, no contexto das migrações internas do Brasil, como uma das principais áreas de imigração. No entanto, na Tabela 1, percebe-se claramente que a área de atração, à qual se referem os autores, corresponde, na verdade, ao Estado da Guanabara (atual cidade do Rio de Janeiro), que, entre 1889 e 1960, era a Capital da República. 0 antigo Estado do Rio de Janeiro apresentou Razão de Sobrevivência Global negativa para a migração interna até a década de 1940; apenas nas décadas de 1950 e 1960 esse indicador apresentou-se positivo para essa área.

A partir dessas informações, infere-se que, apenas a partir da década de 1950, o interior fluminense, mais notadamente o Vale do Paraíba do Sul, que passava por intenso processo de industrialização com a instalação, em 1941, e início das operações, em 1946, da Companhia Siderúrgica Nacional (CSN) em Volta Redonda, e a região dos Lagos, mais notadamente Cabo Frio, com a instalação da Companhia Nacional de Álcalis em 1943 (Silva, 2012), transformaram-se em importantes áreas de atração imigratória.

A atratividade migratória exercida pelo Estado do Rio de Janeiro foi também constatada por Brito (2002). Segundo o autor, o Rio de Janeiro se

\footnotetext{
${ }^{2}$ Em 1980, o Estado do Rio de Janeiro contava com 64 municípios, tendo esse número se elevado para 70 em 1991, para 91 em 2000 e para 92 em 2010 (Magalhães, 2007).
} 
Tabela 1 - Estimativa de Sobrevivência Global Intercensitária da Migração Interna Líquida, segundo Estados, para brasileiros natos (expressas como percentagem da população nos anos dos (ensos - 1872/1970)

\begin{tabular}{cccccccc}
\hline \multicolumn{1}{c}{ UF } & $\mathbf{1 8 7 2 - 1 8 9 0}$ & $\mathbf{1 8 9 0 - 1 9 0 0}$ & $\mathbf{1 9 0 0 - 1 9 2 0}$ & $\mathbf{1 9 2 0 - 1 9 4 0}$ & $\mathbf{1 9 4 0 - 1 9 5 0}$ & $\mathbf{1 9 5 0 - 1 9 6 0}$ & $\mathbf{1 9 7 0 - 1 9 8 0}$ \\
\hline Rio de Janeiro & $-8,93$ & $-11,35$ & 0,4 & $-7,47$ & $-1,06$ & 8,53 & 5,92 \\
Guanabara & 33,45 & 22,24 & 9,81 & 29,45 & 22,6 & 15,68 & 11,25 \\
\hline
\end{tabular}

Fonte: Graham \& Holanda, 1980, p. 741.

destacou, nos períodos de 1940-1950, 1950-1960 e 1960-1970, como uma das principais áreas de atração populacional do Brasil, ao lado de São Paulo, do Paraná e da região Centro-Oeste. No caso do Rio de Janeiro e São Paulo, trata-se dos Estados brasileiros que primeiro se industrializaram; no caso do Paraná e da região Centro-Oeste, por serem áreas de fronteiras agrícolas. Essas características implicaram em uma grande diversidade socioeconômica e de processos de seletividade entre tais fluxos migratórios.

Brito (2002) demonstra, empiricamente, que o Rio de Janeiro foi, ao longo do tempo, perdendo o seu poder de atração populacional. Utilizando dados de migração de última etapa, estimou, para o Rio de Janeiro, no período de 1960-1970, um saldo migratório da ordem de 1.030.464 indivíduos, tendo este se reduzido, segundo suas estimativas, para 392.614 ndivíduos entre 1970-1980. No âmbito desta pesquisa, estimou-se o saldo migratório interestadual para o Rio de Janeiro para os períodos de 1981-1991, 1990-2000 e 2000-2010 e observou-se, para o período de 1981-1991, um saldo migratório negativo da ordem de -77.476 indivíduos (Tabela 2).

Naturalmente, ao analisar o comportamento da imigração no Estado do Rio de Janeiro para o período de 1870-1991, surge a inquietação em relação aos determinantes de sua perda de atração populacional. Em outras palavras, que fatores explicariam a mudança do Rio de Janeiro de receptor a fornecedor líquido de população para outros Estados brasileiros? Para Oliveira (2010), esse fato se relaciona aos seguintes processos, de caráter estrutural:

$\checkmark$ Crise na lavoura cafeeira, no final do século XIX e início do século XX;

$\checkmark$ Perda de poder político, no cenário nacional, com a transferência da capital federal para Brasília;

$\checkmark$ Fusão do Estado da Guanabara com o Estado do Rio de Janeiro, duas unidades da federação
Tabela 2 - Rio de Janeiro: Imigrantes, Emigrantes e Saldo Migratório Interestadual (1960-2010)

\begin{tabular}{cccc}
\hline Decênio & Imigrantes & Emigrantes & Saldo Migratório \\
\hline $1960-1970^{1}$ & 1.403 .737 & 373.273 & 1.030 .464 \\
$1970-1980^{1}$ & 850.309 & 457.695 & 392.614 \\
$1981-1991^{2}$ & 498.656 & 576.132 & -77.476 \\
$1990-2000^{2}$ & 749.087 & 620.496 & 128.591 \\
$2000-2010^{2}$ & 676.527 & 565.777 & 110.750 \\
\hline
\end{tabular}

IBRITO, 2002. ${ }^{2}$ BBGE - Censos Demográficos de 1991, 2000 e 2010.

significativamente estruturalmente distintas, implicando no aprofundamento das contradições internas já existentes;

$\checkmark$ Crise do petróleo, do final da década de 1970;

$\checkmark$ Redução dos investimentos em infraestrutura, previstos no II Plano Nacional de Desenvolvimento (1975-1979), como uma consequência da redução da capacidade de investimento do governo brasileiro, em decorrência da crise do petróleo;

$\checkmark$ Crise econômica da década de 1980, que afetou profundamente o Estado do Rio de Janeiro, cuja economia era, naquele período, muito dependente da produção de 'bens-salário' para o mercado local.

O saldo migratório interestadual negativo foi observado apenas no período de 1981-1991. Nas décadas de 1990 e 2000, o Estado do Rio de Janeiro voltou a exibir saldos migratórios positivos, mas atraindo apenas relativamente poucos imigrantes interestaduais - segundo o Censo de 2010 (IBGE, 2010), apenas $6 \%$ do total dos imigrantes internos brasileiros -, não mais se destacando entre as principais áreas de atração populacional do país. 
Para Simões \& Amaral (2011, p. 554), essa (re)inversão do saldo migratório estadual se deve ao aumento da capacidade de retenção populacional, que, por sua vez, reflete "uma provável reorganização e redinamização econômica do território fluminense", caracterizada pela "desconcentração-concentrada" da atividade industrial, iniciada no Brasil no final da década de 1960.

Ainda que o que tenha ocorrido em relação redistribuição espacial da atividade industrial esteja longe de caracterizar uma real desconcentração espacial da indústria brasileira, esse processo foi determinante na reconfiguração das migrações internas a partir da década de 1970, uma vez que propiciou o surgimento de novas centralidades urbanas, não metropolitanas. Como consequência, houve uma redução do ritmo de crescimento dos núcleos (metrópoles) e das periferias (demais municípios das regiões metropolitanas, excluindo-se a metrópole) das regiões metropolitanas mais antigas ${ }^{3}$ e, simultaneamente, a aceleração, ainda que tímida, do crescimento do interior.

No Estado do Rio de Janeiro, como se pode notar na Tabela 3, a Região Metropolitana do Rio de Janeiro (RMRJ), que, na década de 1970, cresceu a um ritmo médio anual de 2,45\%, apresentou, na década de 2000 , ritmo de crescimento de $0,86 \%$ ao ano. A variação dessa taxa reflete não apenas a queda da fecundidade, mas também o redirecionamento dos fluxos migratórios em direção ao Rio de Janeiro e, é claro, dentro dele.

Observe-se, na Tabela 3, a redução dos ritmos de crescimento do município do Rio de Janeiro (núcleo da RMRJ) de 1,82\%, entre 1970-1980, para 0,76\%, entre 2000-2010, e dos demais municípios da RMRJ (periferia) de 3,33\%, entre 1970-1980, para 0,96\%, entre 2000-2010, e o aumento do ritmo de crescimento do interior, que, no período de 2000-2010, cresceu em $1,83 \%$ ao ano, taxa de crescimento praticamente idêntica àquela observada para o próprio interior na década de 1970 (Baeninger, 1999). Esses resultados indicam a desaceleração dos processos de metropolização (concentração da população em áreas metropolitanas) e de periferização (processo associado ao contexto metropolitano, caracterizado

\footnotetext{
${ }^{3}$ As Regiões Metropolitanas mais antigas foram instituídas pela Lei Complementar Federal no 14 de 1973. São elas: São Paulo, Belo Horizonte, Porto Alegre, Recife, Salvador, Curitiba, Belém e Fortaleza (Brasil, 1973). A Região Metropolitana do Rio de Janeiro, também antiga, foi criada pela Lei Complementar $\mathrm{n}^{\circ}$ 20 de 1974 (Brasil, 1974).
}

Tabela 3 - Rio de Janeiro: Ritmo de Crescimento Populacional Médio Anual, segundo as espacialidades (1970-2010)

\begin{tabular}{ccccc}
\hline Espacialidades & $\begin{array}{c}\mathbf{1 9 7 0}- \\
\mathbf{1 9 8 0}\end{array}$ & $\begin{array}{c}\mathbf{1 9 8 0} \\
\mathbf{1 9 9 1}\end{array}$ & $\begin{array}{c}\mathbf{1 9 9 1 -} \\
\mathbf{2 0 0 0 ^ { 2 }}\end{array}$ & $\begin{array}{c}\mathbf{2 0 0 0} \\
\mathbf{2 0 1 0 ^ { 2 }}\end{array}$ \\
\hline RMRJ & 2,45 & 1,26 & 1,26 & 0,86 \\
Núcleo & 1,82 & 0,66 & 0,76 & 0,76 \\
Periferia & 3,33 & 2,02 & 1,81 & 0,96 \\
Interior & 1,82 & 1,58 & 1,61 & 1,83 \\
UF & 2,3 & 1,13 & 1,33 & 1,06 \\
\hline
\end{tabular}

'BAENINGER, 1999, p. 540. 2IBGE - Censos Demográficos de 1991, 2000 e 2010.

por um crescimento mais acelerado da população dos municípios periféricos comparativamente ao ritmo de crescimento do núcleo) e a aceleração - ininterrupta e crescente - do processo de interiorização a partir da década de 1980. Como se mencionou, essas taxas refletem, sobretudo, o (re)direcionamento dos fluxos migratórios - interestaduais e intraestaduais - no Estado do Rio de Janeiro.

Conforme mencionado, nos Censos Demográficos de 1991, 2000 e 2010 foram captados os imigrantes interestaduais de última etapa, no Estado do Rio de Janeiro, segundo o município de destino, mas, para efeitos analíticos, os resultados foram dispostos - na Tabela 4-em microrregiões e mesorregiões. Para essas estimativas, foram considerados todos os imigrantes com menos de dez anos de residência no município e com residência anterior em outra unidade da federação. Procedendo dessa forma, excluíram-se os imigrantes interestaduais que, nos respectivos períodos intercensitários, realizaram um movimento migratório intraestadual.

Em 1991, praticamente 84\% dos imigrantes tiveram a mesorregião Metropolitana como destino, com destaque para a microrregião "Rio de Janeiro", constituída por 16 municípios metropolitanos, incluindo a cidade do Rio de Janeiro. No período de 1980-1991, a capital Fluminense absorveu um total de 283.334 imigrantes, ou seja, $57 \%$ do total de imigrantes internos do Estado do Rio de Janeiro. Apenas $16 \%$ dos imigrantes se dirigiram para as áreas interioranas, mais notadamente para o "Vale do Paraíba” no Sul Fluminense, onde se destacam como importantes áreas de atração os municípios de Barra Mansa, Resende e Volta Redonda. 
Tabela 4 - Rio de Janeiro: Imigrantes interestaduais, segundo a microrregião e a mesorregião de destino $(1991,2000,2010)$

\begin{tabular}{|c|c|c|c|}
\hline Microrregião/Mesorregião & 1991 & 2000 & 2010 \\
\hline Bacia de São João & 0,3 & 0,6 & 2,1 \\
\hline Lagos & 1,7 & 3,6 & 4,2 \\
\hline Baixadas Litorâneas & 2 & 4,1 & 6,4 \\
\hline Cantagalo-Cordeiro & 0,2 & 0,2 & 0,3 \\
\hline Nova Friburgo & 0,7 & 0,7 & 0,8 \\
\hline Santa Maria Madalena & 0 & 0 & 0,1 \\
\hline Três Rios & 1,2 & 1 & 0,9 \\
\hline Centro Fluminense & 2,1 & 2 & 2,1 \\
\hline Itaguá & 0,9 & 1,4 & 1,9 \\
\hline Macacu-Caceribu & 0,2 & 0,5 & 0,4 \\
\hline Rio de Janeiro & 80 & 76 & 71,6 \\
\hline Serrana & 2,3 & 2,5 & 1,7 \\
\hline Vassouras & 0,5 & 0,7 & 0,6 \\
\hline Metropolitana do Rio de Janeiro & 83,9 & 81 & 76,1 \\
\hline Itaperuna & 0,9 & 1 & 1,2 \\
\hline Santo Antônio de Pádua & 0,4 & 0,5 & 0,5 \\
\hline Noroeste Fluminense & 1,2 & 1,5 & 1,7 \\
\hline Campos dos Goytacazes & 1,2 & 1,5 & 1,9 \\
\hline Macaé & 1,1 & 1,9 & 4 \\
\hline Norte Fluminense & 2,3 & 3,4 & 5,9 \\
\hline Baía da Ilha Grande & 1,4 & 2,2 & 2,4 \\
\hline Barra do Piraí & 0,8 & 0,7 & 0,6 \\
\hline Vale do Parába Fluminense & 6,4 & 5,1 & 4,8 \\
\hline Sul Fluminense & 8,5 & 8 & 7,8 \\
\hline Rio de Janeiro (\%) & 100,00 & 100,00 & 100,00 \\
\hline Rio de Janeiro (absoluto) & 498.656 & 749.093 & 676.528 \\
\hline
\end{tabular}

Fonte: IBGE - Censos Demográficos (1991, 2000 e 2010).

Observam-se, entre 1991 e 2010, mudanças substanciais na distribuição espacial (em termos relativos) dos imigrantes no Estado. A mesorregião Metropolitana diminuiu seu poder de atração e sua capacidade de absorção imigratória, prática e exclusivamente, pela redução do poder de atração da microrregião "Rio de Janeiro" e, sobretudo, da própria metrópole que, entre 2000-2010, atraiu pouco mais de $46 \%$ do total de imigrantes interestaduais. A redução da participação relativa dessa mesorregião na absorção dos imigrantes foi compensada pelo aumento do poder de atração da "Baixada Litorânea", com destaque para os municípios de Rio das Ostras e Cabo Frio, e do Norte Fluminense, onde se destacam como importantes áreas de destino os municípios de Macaé e Campos dos Goytacazes. Ressalte-se que o Sul Fluminense se mantém relativamente estável enquanto área de atração populacional ao longo do período.

\section{Rio de Janeiro: migrações intraestaduais (1991-2010)}

Como se mencionou, nesta seção foram utilizados os Censos Demográficos de 1991 e 2010 por limitações de ordem metodológica impostas pelo Censo Demográfico de 2000.

Os resultados dos Censos Demográficos de 1991 e 2010 mostram que, no Estado do Rio de Janeiro, nos períodos de 1981-1991 e 2000-2010, as migrações intraestaduais apresentaram enorme magnitude, superando, em volume, os fluxos migratórios interestaduais.

A tendência para o papel desempenhado pela proximidade geográfica na definição dos movimentos migratórios já havia sido apontada por Rigotti \& Amorim (2002). Para se analisarem as migrações intraestaduais, considerando o papel desempenhado pela proximidade geográfica, optou-se, nesse caso, por adotar uma divisão espacial mais detalhada, a saber: movimentos migratórios de curtíssima distância, sob a designação de "migração intramicrorregional", definida como os movimentos migratórios entre municípios de uma mesma microrregião; e de curta distância, admitidos como a migração intraestadual, excluindo-se as migrações intramicrorregionais.

Entre 1981-1991, a migração interna no Estado do Rio de Janeiro envolveu um total de 823.769 indivíduos, dos quais 492.088 realizaram movimentos migratórios intramicrorregionais ${ }^{4}$ e 331.681 indivíduos realizaram movimentos migratórios intraestaduais, excluindo-se os primeiros (Tabela 5). Considerando-se a migração bruta, verifica-se que, apenas na "Metropolitana" e no Vale do Paraíba, os fluxos intramicrorregionais, de curtíssima distância, superaram os intraestaduais de curta distância. Nas demais, as maiores trocas deram-se com municípios de outras microrregiões e mesorregiões. Significa dizer que, naquele período, as

\footnotetext{
${ }^{4}$ Em cada Censo, trabalhou-se com as respectivas configurações espaciais.
} 


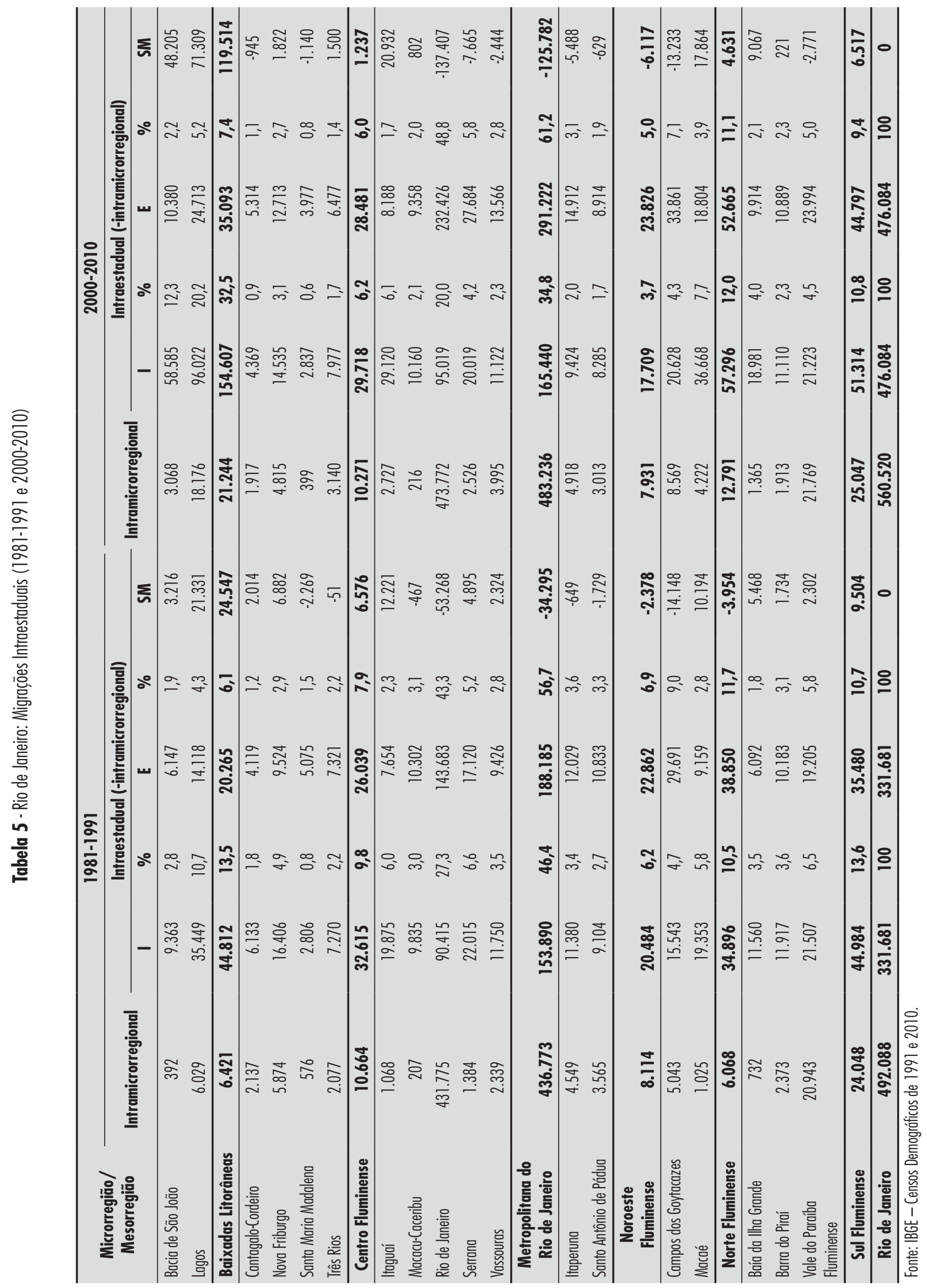

urbe. Revista Brasileira de Gestão Urbana (Brazilian Journal of Urban Management), 2018 jan./abr., 10(1), 124-139 
forças de atração que os municípios exerciam sobre a população residente em municípios próximos, propensa a migrar, eram baixas. É possível que a imperfeição da informação levasse muitos indivíduos a se aventurarem para municípios mais longínquos, à procura de oportunidades no mercado de trabalho, as quais já sabiam restritas ou mesmo inexistentes nos municípios mais próximos, para os quais as informações disponíveis são, em princípio, mais amplas, como sugere Lee (1980):

[...] pessoas que vivem numaárea têm conhecimento imediato e, frequentemente, de longo tempo sobre a área, sendo capazes de fazer uma avaliação mediata e sem precipitações sobre a mesma. Isto não ocorre necessariamente com relação aos fatores associados à área de destino. 0 conhecimento da área de destino raramente é exato; de fato, algumas das vantagens e desvantagens da área são perceptíveis ao se viver nela. Portanto, existe um elemento de ignorância e, inclusive, de mistério sobre a área de destino pelo que sempre se faz presente alguma incerteza acerca da receptividade que $o$ migrante teria na nova área (Lee, 1980, p. 102).

Na mesorregião Metropolitana, a migração intramicrorregional envolveu 436.773 indivíduos, dos quais 431.775 apenas na microrregião "Rio de Janeiro", ressaltando que, nesse caso, a maior emigração deu-se do grande centro para outros municípios da própria Região Metropolitana, caracterizando o processo de periferização (Tabela 5). A "Metropolitana do Rio de Janeiro" atraiu 46,4\% dos imigrantes intraestaduais, mas, por se destacar como uma importante área de emigração - 56,7\% do total de emigrantes intraestaduais -, seu saldo migratório apresentou-se negativo em -34.295 indivíduos no decênio 1981-1991. Para o município do Rio de Janeiro, estimou-se um saldo migratório total (curtíssima e curta distância) de -242.783 pessoas e, como se mencionou, a maior parte de seus emigrantes teve como destino algum município da própria Região Metropolitana.

Os municípios da "Baixada Litorânea" atraíram $13,5 \%$ dos imigrantes intraestaduais. Com uma emigração relativamente baixa $(6,1 \%)$, seu saldo migratório apresentou-se positivo em 24.527 indivíduos. Comportamento semelhante - alta atração e baixa expulsão - verifica-se no Sul Fluminense, que, no contexto das migrações intraestaduais, também apresentou saldo migratório positivo e elevado. Já o Centro Fluminense, que, apesar de atrair um número significativo de imigrantes, tem baixa capacidade de retenção populacional, apresentando saldo migratório positivo, mas relativamente baixo. Nas regiões Norte e Noroeste, o saldo migratório intraestadual apresentou-se negativo, indicando uma emigração relativamente alta, se comparada à imigração, a partir desses municípios.

Entre 1981-1991 e 2000-2010, observaram-se mudanças significativas nas características das migrações intraestaduais no Estado do Rio de Janeiro, das quais se destacam:

(i) 0 aumento significativo do volume: segundo o Censo de 2010, na última década um total de 1.036.632 indivíduos mudou de residência entre municípios do Estado do Rio de Janeiro, ressaltando-se que o movimento migratório de 560.520 indivíduos se restringiu a municípios da mesma microrregião.

(ii) A redução da importância relativa das migrações intramicrorregionais de 59,7\%, entre 1981-1991, para 54,1\%, entre 2000-2010, indicando uma maior predisposição dos migrantes intraestaduais para percorrerem distâncias mais longas, em seus deslocamentos, dentro do Estado do Rio de Janeiro.

(iii) 0 expressivo aumento do poder de atração populacional exercido pelos municípios da Baixada Litorânea, seguido apenas de inexpressivo aumento das emigrações. Em termos líquidos, as Baixadas Litorâneas experimentaram, no decênio 2000-2010, o maior ganho populacional fluminense, da ordem de 119.514 novos habitantes.

(iv) A redução do poder de atração e do poder de expulsão exercido pela região Central Fluminense, que apresentou ganho populacional líquido de apenas 1.237 indivíduos no decênio 2000-2010, indicando que as migrações intraestaduais influenciam cada vez menos no volume e na determinação dos ritmos de crescimento populacional da região.

(v) A redução do poder de atração e aumento do poder de expulsão da mesorregião "Metropolitana do Rio de Janeiro", que, na última década, apresentou saldo migratório negativo da ordem de -125.782 indivíduos. 
(vi) No interior da mesorregião Metropolitana, o comportamento da microrregião do "Rio de Janeiro", com aumento expressivo da imigração e da emigração relativas, resultando em um saldo migratório negativo de -137.497 indivíduos - número significativamente superior àquele observado no decênio 1981-1991. Podem-se apontar como consequências desse comportamento o arrefecimento, ainda que tímido, da periferização e a aceleração, também ainda que tímida, da interiorização, principalmente em direção à Baixada Litorânea, espacialmente contígua à Região Metropolitana.

(vii) Permanência da região Noroeste como área de emigração líquida, com aumento expressivo de seu saldo migratório negativo.

(viii) O Norte Fluminense como área de atração populacional dos migrantes intraestaduais, com um saldo de 4.631 novos habitantes. No entanto, é preciso chamar a atenção para as diferenças significativas entre as dinâmicas migratórias de Macaé e Campos dos Goytacazes no contexto das migrações intraestaduais. Segundo os Censos de 1991 e 2010, a microrregião de Macaé apresentou maior poder de atração e retenção populacional, comparativamente à microrregião de Campos. Seu saldo migratório intraestadual foi, nos dois períodos, positivo, elevando-se de 10.194, entre 1981-1991, para 17.864, no período de 2000-2010. Já Campos dos Goytacazes apresentou, nos dois períodos, saldo migratório intraestadual negativo, de -14.148 indivíduos em 1991 e de -13.233 em 2010. Significa dizer que o saldo migratório intraestadual positivo do Norte Fluminense deve-se, na realidade, à dinâmica migratória da microrregião de Macaé.

(ix) A redução do poder de atração e do poder de expulsão do Sul Fluminense, de forma tal que seu saldo migratório reduziu-se comparativamente ao período de 1981-1991, o que também implica em uma influência cada vez menor dos movimentos migratórios na definição do volume e do ritmo de crescimento populacional dessa região, tal como ocorreu na região Central Fluminense.

\section{Rio de Janeiro: principais áreas de expansão urbana}

Para identificar as principais áreas de expansão urbana do Estado do Rio de Janeiro, serão utilizados três indicadores: o saldo migratório total, dado pela soma dos saldos migratórios interestaduais e intraestaduais municipais, estando incluídos, portanto, os movimentos migratórios de curtíssimas e de curtas distâncias; as taxas líquidas de migração, que indicam o "peso" dos movimentos migratórios sobre os ritmos de crescimento municipais, tendo em vista que volumes migratórios iguais influenciam de forma diferenciada populações de tamanhos distintos; e, finalmente, os ritmos de crescimento populacional, segundo a situação do domicílio, que sumarizam a influência das três variáveis da dinâmica demográfica e indicam a direção e velocidade do crescimento populacional, permitindo-se identificar os principais eixos da expansão urbana fluminense nos períodos estudados.

Como se está trabalhando com resultados consolidados, neste caso também só serão analisados os períodos de 1981-1991 e 2000-2010, pelo mesmo motivo já explicitado anteriormente. Por razões didático-metodológicas, as informações serão disponibilizadas por meio de mapas temáticos, muito embora no banco de dados dos autores desta pesquisa constem as tabelas com todas as informações detalhadas. No entanto, considera-se que seria pouco produtivo e exaustivo para o leitor disponibilizá-las aqui.

Observe a Figura 1 com o saldo migratório total dos municípios fluminenses no decênio 1981-1991. Naquele período, o maior expulsor líquido de população foi de fato o município do Rio de Janeiro, com um saldo migratório total de -360.430 indivíduos. Ressalta-se que esse município era expulsor populacional tanto no contexto das migrações interestaduais quanto intraestaduais e que suas maiores perdas populacionais se deram, principalmente, para outros municípios do próprio Estado, mais notadamente para aqueles da própria Região Metropolitana, como se discutiu na seção em que se tratou das migrações intraestaduais. Na Região Metropolitana, Niterói também se destacou por seu saldo migratório negativo (em torno de -16 mil habitantes), também nos contextos interestaduais e intraestaduais.

Praticamente toda a região Noroeste, com exceção de Itaperuna, Porciúncula e Miracema, todos os municípios da microrregião de Campos, no Norte 


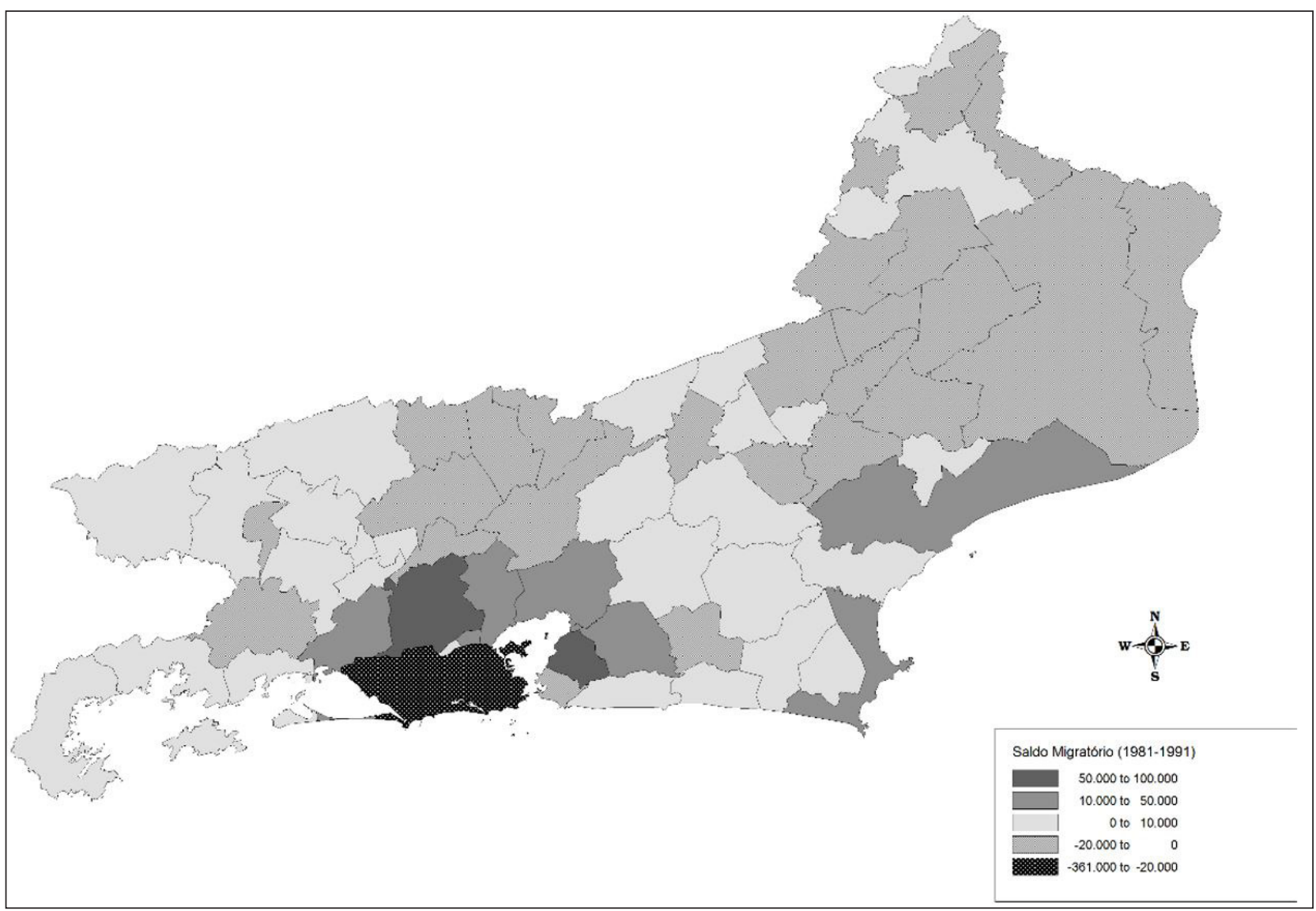

Figura 1 - Rio de Janeiro: Saldo Migratório Total (1981-1991)

Fonte: Elaboração própria a partir de dados do IBGE - Censo Demográfico 1991 (BBGE, 1991).

Fluminense, e todos os municípios das microrregiões Santa Maria Madalena e Três Rios, no Centro Fluminense, destacam-se como áreas de expulsão populacional, exibindo saldos migratórios totais negativos.

Como áreas de atração populacional destacam-se todos os municípios da região dos Lagos e da Bacia de São João, nas Baixadas Litorâneas; a (grande) maioria dos municípios da Região Metropolitana (inclusive é aqui que se observam os saldos migratórios positivos mais elevados, em números absolutos) e do Sul Fluminense; e os municípios da microrregião de Macaé, no Norte Fluminense.

Entre 1981-1991 e 2000-2010, destacam-se como principais alterações, observando-se as Figuras 1 e 2: a redução do número de municípios expulsores de população no Centro Fluminense, ressaltando-se que aqueles que apresentaram saldos positivos exibiram baixos valores; a redução, em valores absolutos, do saldo migratório positivo dos municípios da Região Metropolitana; na RMRJ, o município do Rio de Janeiro permanece como principal expulsor, tendo o seu saldo migratório total se reduzido para aproximadamente -203 mil habitantes; ao lado do Rio de Janeiro, destacam-se pelos seus saldos migratórios negativos os municípios de Niterói e, nesse período, de Petrópolis, na microrregião Serrana.

Na região Noroeste, Itaperuna e Miracema passaram a apresentar saldo migratório total negativo. Na região Norte, apenas Campos e São Francisco do Itabapoana se destacaram como expulsores populacionais líquidos.

Finalmente, no Sul Fluminense, Valença, que antes era um município de atração populacional líquida, passou a se posicionar, ao lado de Barra Mansa e Volta Redonda, como área de expulsão, ressaltando-se que os saldos migratórios negativos desses dois últimos municípios se tornaram ainda maiores quando comparados aos resultados de 1981-1991.

Como se deseja analisar o processo de expansão urbana, saldos migratórios absolutos, apesar de destacarem entre os principais indicadores dos movimentos migratórios, são insuficientes. É preciso analisar, nesse caso, o impacto das migrações sobre 


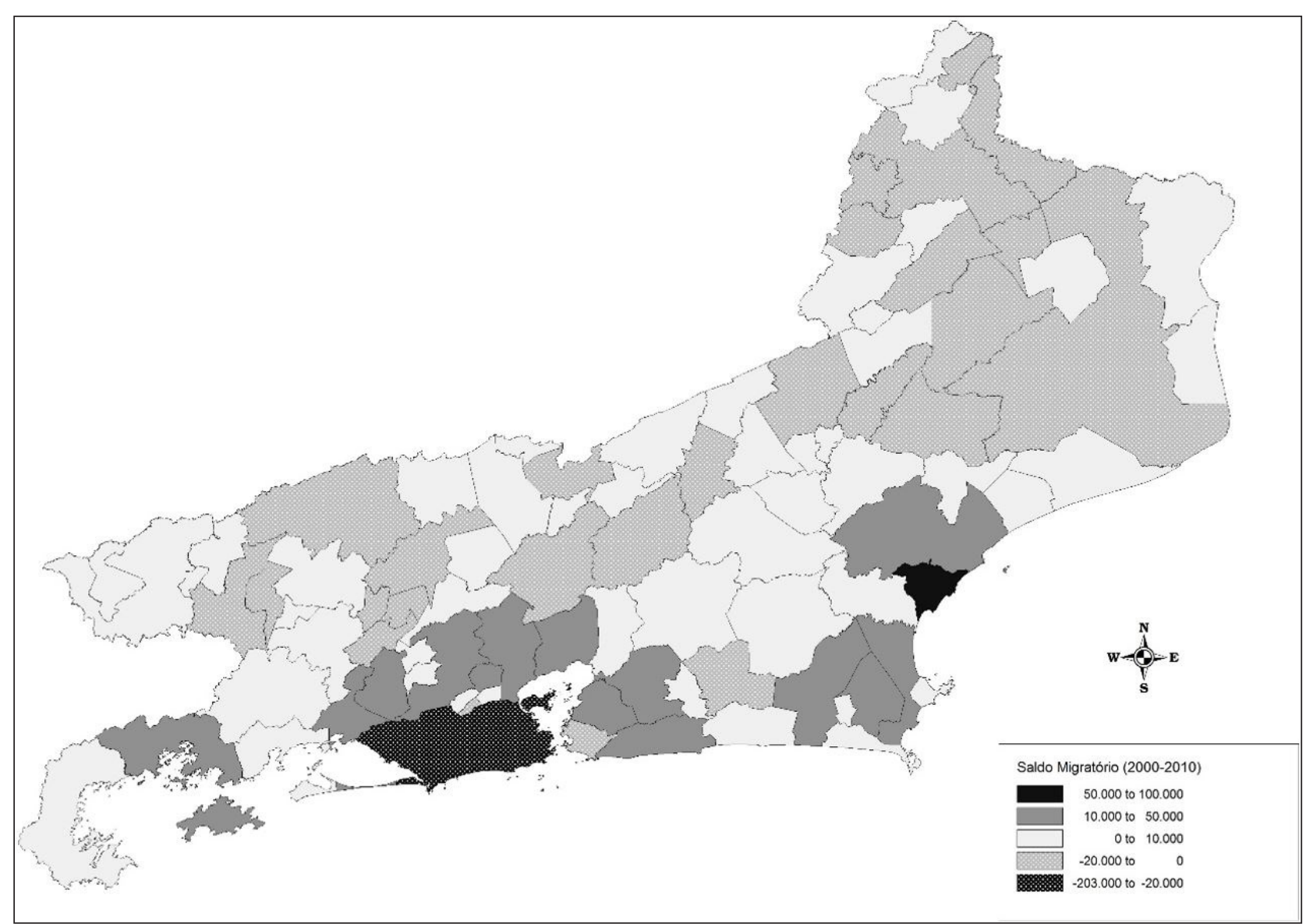

Figura 2 - Rio de Janeiro: Saldo Migratório Total (2000-2010)

Fonte: Elaboração própria a partir de dados do IBGE - Censo Demográfico 2010 (IBGE, 2010).

os ritmos de crescimento municipais, portanto as taxas líquidas de migração (estimadas com dados de migração intermunicipais; sendo assim, as migrações rurais-urbanas ocorridas dentro de um mesmo município não influenciaram nos resultados). Em todos os municípios com saldos migratórios negativos, as migrações líquidas contribuíram para o arrefecimento do ritmo de crescimento populacional. Nas áreas de atração populacional, o crescimento populacional torna-se mais acelerado, o que na prática se traduz na maior necessidade de planejamento urbano.

No Estado do Rio de Janeiro, entre 1981-1991 (Figura 3), apenas em um número reduzido de municípios as migrações tiveram um impacto mais expressivo sobre os respectivos ritmos de crescimento populacional: Saquarema, São Pedro da Aldeia, Casimiro de Abreu e Cabo Frio, nas Baixadas Litorâneas; Cordeiro e Duas Barras, no Centro Fluminense; Mangaratiba, Itaguaí, Maricá, Magé, Itaboraí, São Gonçalo, Nova Iguaçu e Engenheiro Paulo Frontin, na mesorregião Metropolitana do Rio de Janeiro; Conceição de Macabu,
Casimiro e Macaé, no Norte Fluminense; e Piraí, no Sul Fluminense.

No caso das taxas líquidas de migração, as mudanças são extremamente significativas do decênio 1981-1991 para 2000-2010. No último decênio, pode-se observar que as migrações internas (interestaduais e intraestaduais) impactaram, de forma mais significativa, no ritmo de crescimento de um número maior de municípios (Figura 4). Taxas líquidas de migração extremamente altas foram observadas em toda a extensão urbana, que se estende de Araruama e Saquarema, nas Baixadas Litorâneas, a Quissamã e São João da Barra, no Norte Fluminense.

Na região Norte, os municípios que se emanciparam de Macaé nas décadas anteriores se destacaram como áreas de atração populacional e apresentaram taxas líquidas de migração elevadíssimas. 0 caso que mais chama atenção é o de Rio das Ostras, que atraiu mais de 50 mil pessoas, o que implicou em uma taxa líquida de migração da ordem de $48 \%$. 


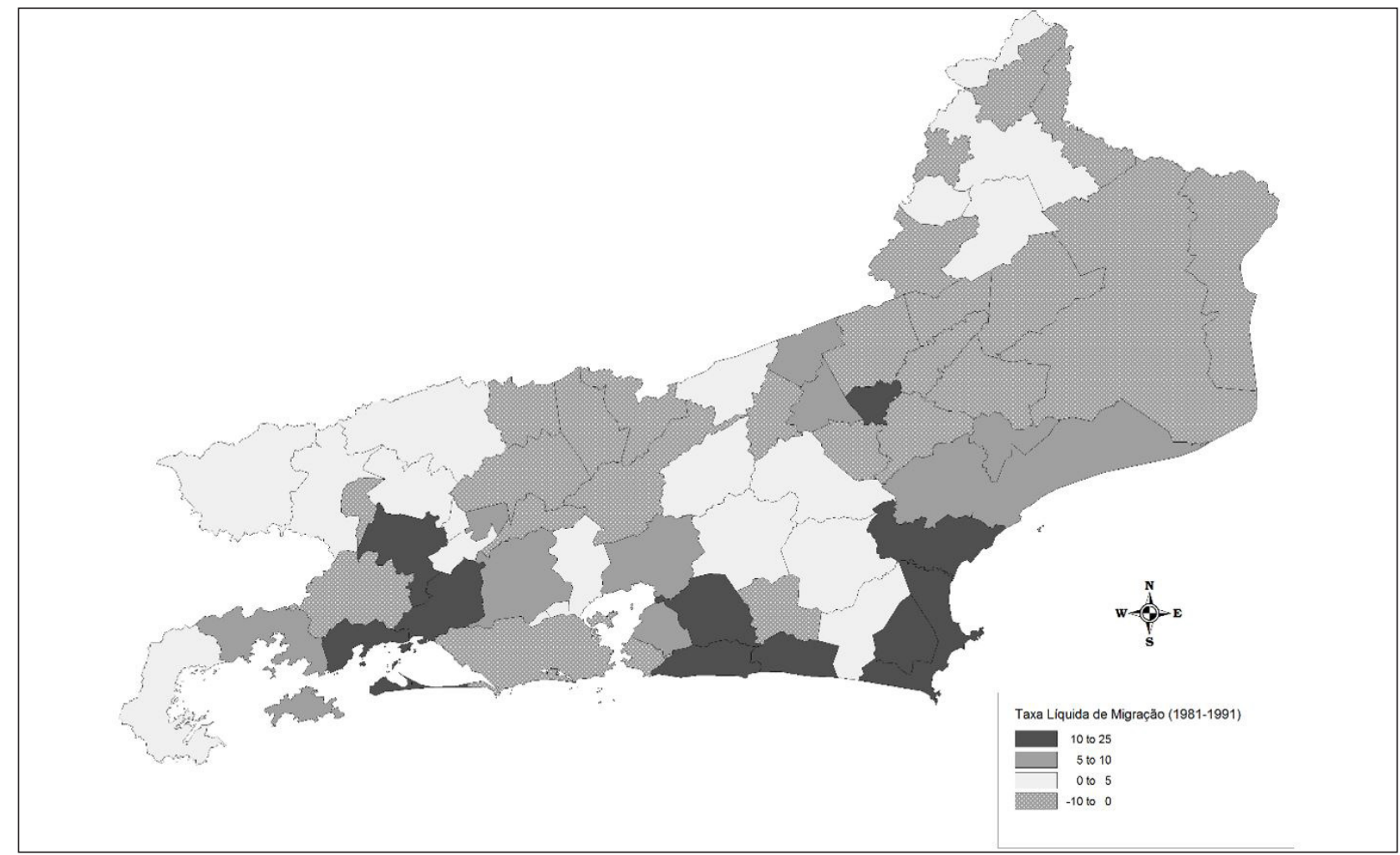

Figura 3 - Rio de Janeiro: Taxa Líquida de Migração (1981-1991)

Fonte: Elaboracç̃o própria a partir de dados do IBGE - Censo Demográfico 1991 (IBGE, 1991).

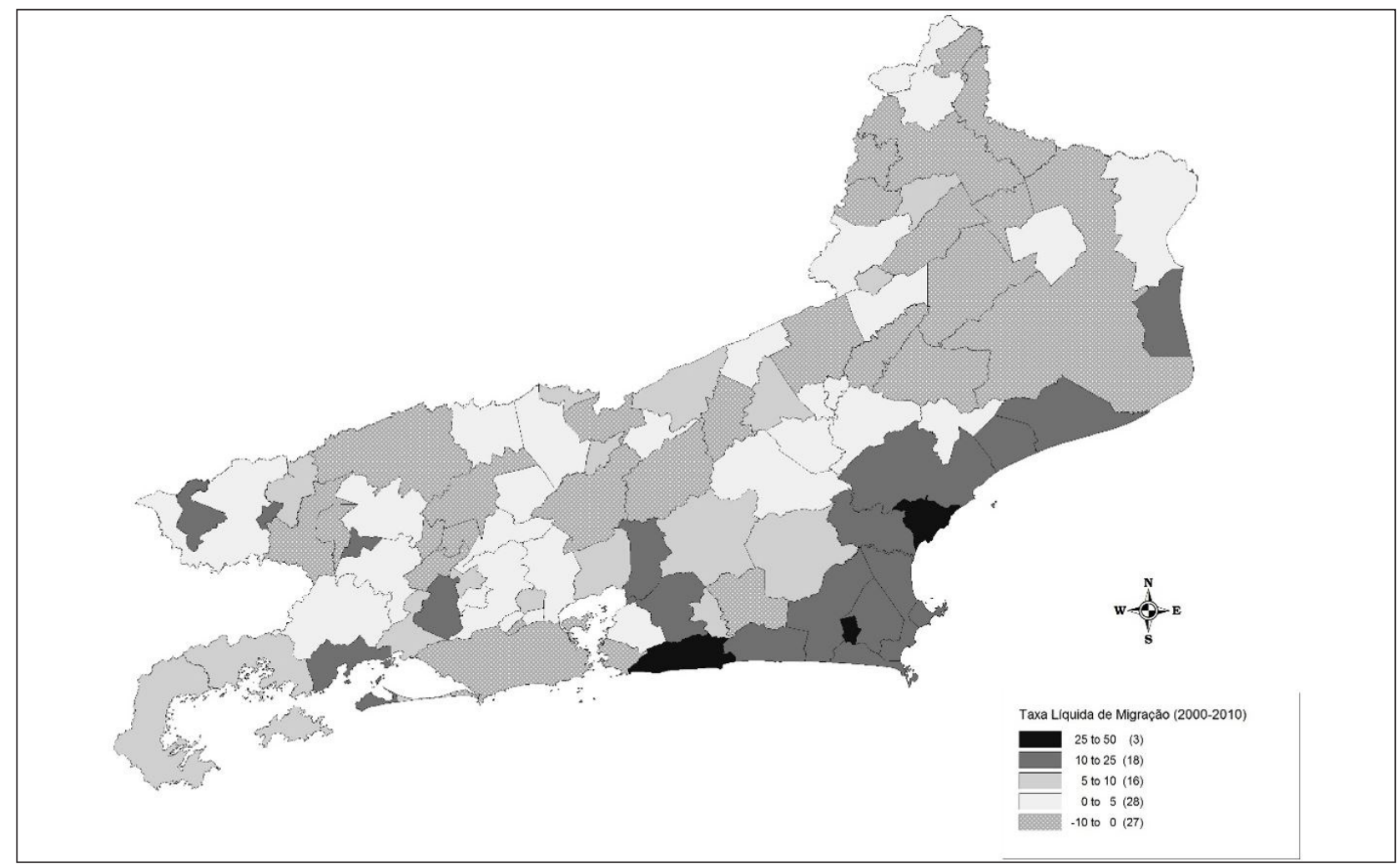

Figura 4 - Rio de Janeiro: Taxa Líquida de Migração (2000-2010)

Fonte: Elaboração própria a partir de dados do IBGE - Censo Demográfico 2010 (IBGE, 2010). 
No período de 1980-1991, a população urbana fluminense cresceu a um ritmo de 1,45\% ao ano, enquanto a população rural reduziu-se a um ritmo médio anual de $3,87 \%$, tendo o crescimento global se dado a um ritmo de 1,5\% ao ano. Naquele período, para apenas 12 municípios as taxas de crescimento da população rural apresentaram-se positivas, lembrando-se que se está tratando de um contingente populacional relativamente pequeno (menos de $5 \%$ da população estadual total). Apesar do crescimento positivo da população rural, em alguns municípios, a redução do grau de urbanização - dado pelo quociente entre população urbana e total - só foi observada em Magé e Nova Friburgo.

Para o período de 2000-2010, os ritmos de crescimento das populações urbanas, rurais e totais fluminenses foram, respectivamente, $1,28 \%$ a.a., $-0,91 \%$ a.a., e 1,20 a.a., sendo somente 20 municípios com crescimento rural positivo, ressaltando-se que, em 2010, a população rural reduziu-se em números absolutos e passou a corresponder a menos de 3,5\% da população total.

Também no decênio 2000-2010, verificou-se, para a maioria dos municípios, um aumento do grau de urbanização. Em alguns, como Arraial do Cabo, Cabo Frio, Carapebus e Casimiro de Abreu, o grau de urbanização se reduziu, mas permaneceu elevado. Em 2010, apenas em Santa Maria Madalena, São Francisco do Itabapoana, São José de Ubá, São José do Vale do Rio Preto, São Sebastião do Alto, Sumidouro e Trajano de Morais a população rural apresentava-se superior à urbana, cabendo observar que, com exceção de São Francisco do Itabapoana (com população superior a 40 mil habitantes em 2010), todos os outros municípios são de pequeno porte.

Muito provavelmente, em ambos os períodos, o crescimento populacional rural positivo de alguns municípios esteve relacionado às "novas espacialidades", ou seja, ao surgimento/expansão de "novas ruralidades"(áreas que, na prática, têm mais características urbanas do que rurais, como é o caso de alguns condomínios fechados, para população de alto nível de renda) e à expansão de bairros populares para áreas ainda consideradas rurais.

É interessante notar que a redução absoluta das populações rurais da maioria dos municípios fluminenses e as taxas relativamente elevadas de crescimento urbano apresentadas podem estar refletindo: (i) em parte, uma mera reclassificação de áreas rurais em urbanas, que porventura tenham ocorrido no período intercensitário, lembrando que essa classificação se dá, no caso brasileiro, por decreto; (ii) as migrações rurais-urbanas dentro de um mesmo município, as quais, apesar de não afetarem seu crescimento global, redistribuem espacialmente a população e alteram o ritmo de crescimento, segundo a situação do domicílio; (iii) as migrações - rurais-urbanas e urbanas-urbanas - intramunicipais, notadamente entre os próprios municípios fluminenses. Significa dizer que as taxas globais de crescimento são determinadas praticamente pelo crescimento urbano, o qual, em um contexto generalizado de queda de fecundidade, está cada vez mais relacionado aos movimentos migratórios internos.

Os resultados das Figuras 5 e 6, que trazem plotadas as taxas globais de crescimento populacional, confirmam o papel determinante das migrações na definição dos eixos de expansão urbana, na medida em que os municípios fluminenses que mais cresceram foram exatamente aqueles em que se verificam as maiores Taxas Líquidas de Migração.

Por meio das Figuras 5 e 6, pode-se inferir que, pelo menos a partir da década de 1980, a principal área de interiorização do crescimento do Estado do Rio de Janeiro corresponde a toda extensão territorial que vai de Saquarema, nas Baixadas Litorâneas, a Quissamã, no Norte Fluminense.

No caso dos municípios da Baixada Fluminense, infere-se, a partir da proximidade espacial com a Região Metropolitana, que, pelo menos no caso de alguns municípios, como Saquarema e Araruama, essa expansão relaciona-se: em parte, ao extravasamento do crescimento populacional da própria Região Metropolitana para áreas interioranas contíguas; em parte, à vocação turística; e, em parte, aos impactos da indústria petrolífera.

No caso dos municípios do Norte Fluminense, essa expansão relaciona-se única e exclusivamente aos impactos da indústria petrolífera.

Em 1973, a Petrobras iniciou a instalação de sua base operacional no município de Macaé, atraindo, como sempre acontece em áreas de desenvolvimento industrial, um significativo número de empresas prestadoras de serviços, tornando-se, portanto, uma importante área de atração populacional, tanto pelas oportunidades de emprego, principalmente se considerar que a mão de obra local não tinha qualificação suficiente para ocupar os novos postos de trabalho, quanto pelo nível de salários pagos aos trabalhadores. 


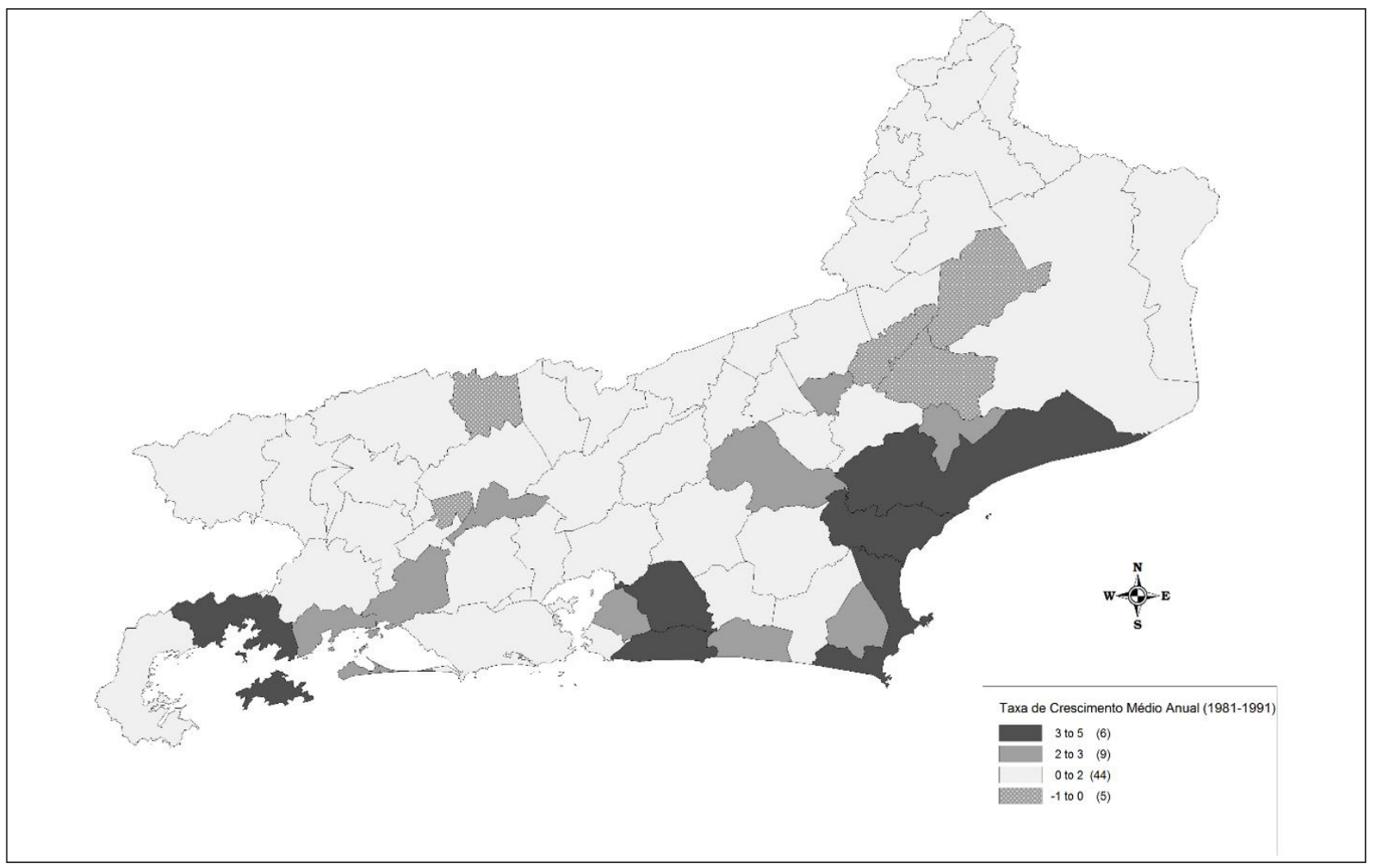

Figura 5 - Rio de Janeiro: Taxa de Crescimento Populacional Médio Anual (1981-1991) Fonte: Elaboração própria a partir de dados do IBGE - Censo Demográfico 1991 (IBGE, 1991).

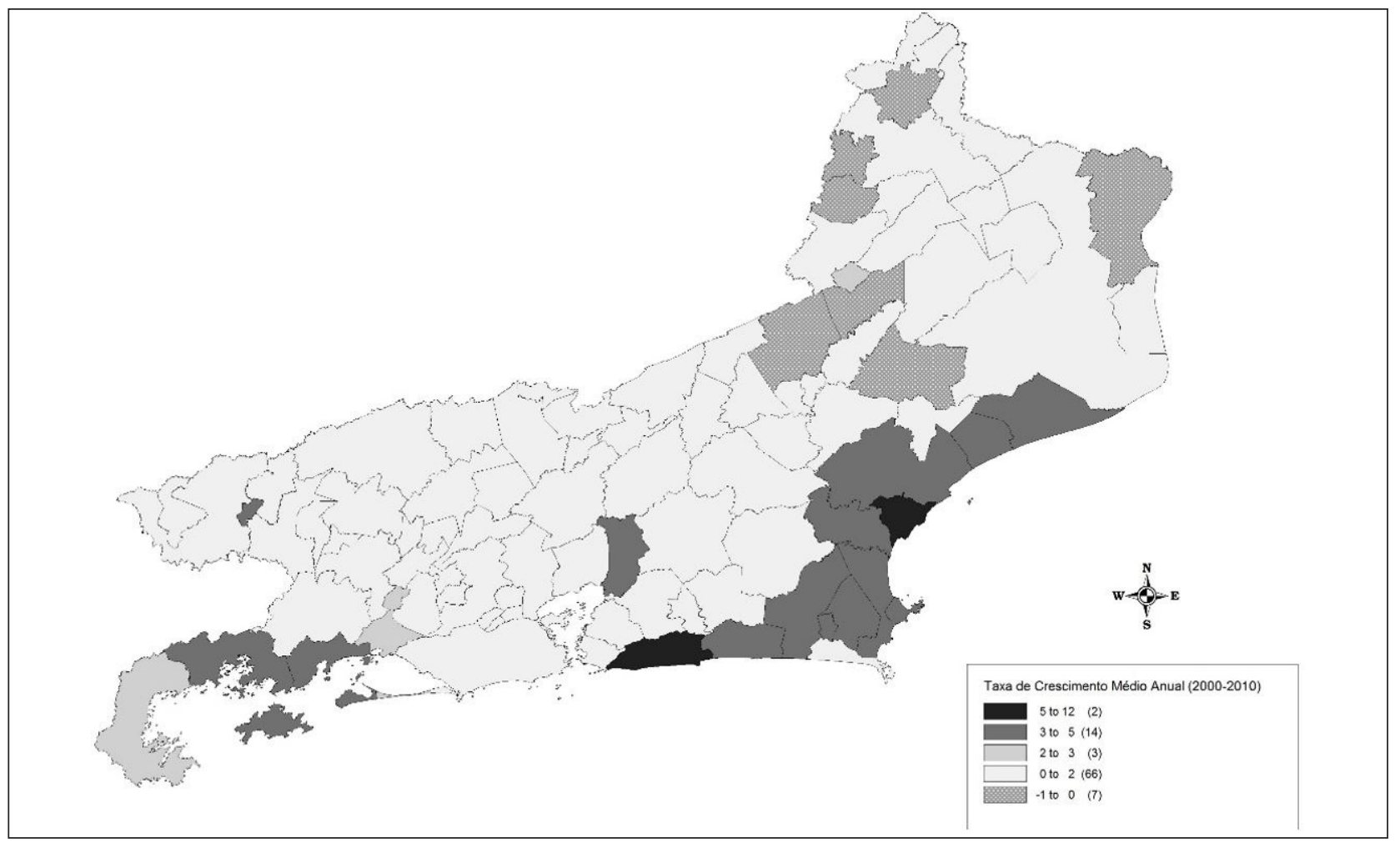

Figura 6 - Rio de Janeiro: Taxa de Crescimento Populacional Médio Anual (2000-2010) Fonte: Elaboraç̃ão própria a partir de dados do IBGE - Censo Demográfico 2010 (IBGE, 2010). 
No caso do Norte Fluminense, de interesse particular para esta pesquisa,

[...] o acelerado crescimento populacional de Macaé é incitado pelo próprio dinamismo econômico do município, que, sendo base da indústria da exploração e produção de petróleo e gás, torna-se um importante destino para muitos migrantes internos. Em relação aos demais municípios, pode-se dizer que o crescimento populacional deles é provocado pelos efeitos das movimentações econômicas de Macaé, pelo comportamento de seus respectivos mercados imobiliários, com ofertas de terras relativamente mais baratas, se comparadas ao preço da terra em Macaé, e pela proximidade espacial em relação a este último, a qual permite a realização de movimentos pendulares de distância e tempo relativamente curtos (Souza \& Terra, 2015, p. 130).

Entre 1981-1991 e 2000-2010, verifica-se, na realidade, a consolidação dessa extensão urbana — de Araruama a Quissamã - como a principal frente de interiorização do crescimento, fato este que justifica sua inclusão entre os vários impactos que a indústria petrolífera tem gerado.

\section{Considerações finais}

Infelizmente, no Brasil, não se dispõem de fontes de dados que tragam informações sobre os movimentos migratórios, desagregadas por municípios, para o período intercensitário. Em virtude dessa lacuna e tendo em vista os objetivos propostos, este estudo limitou-se ao período de 1980-2010, ano de realização do último Censo Demográfico Brasileiro.

No contexto das migrações interestaduais, o Rio de Janeiro não ocupa mais, no cenário nacional, o espaço de centralidade que ocupava até a década de 1960. A partir da década de 1970, apresentou perda de poder de atração populacional, chegando a exibir saldo migratório negativo na década de 1980.

Apesar de, na década de 1990, o Estado do Rio de Janeiro voltar a apresentar saldo migratório interestadual positivo, este é de pequena magnitude, indicando a pequena influência dessas migrações sobre o ritmo de crescimento estadual e, inclusive, sobre o ritmo de crescimento da maioria dos municípios fluminenses.
A partir dessa consideração, infere-se que o papel das migrações interestaduais na definição dos eixos de expansão urbana, nas últimas décadas, é praticamente nulo. As migrações intraestaduais, de grande e crescente magnitude, são as que de fato definem a velocidade e a direção desse processo.

Pelo menos desde a década de 1980, os municípios do litoral Norte Fluminense - Baixadas Litorâneas e Norte Fluminense - são os que apresentam os maiores saldos migratórios positivos, as maiores TLM e as maiores taxas de crescimento populacional, o que os coloca como a principal frente de interiorização do Estado, ressaltando-se que está se referindo a um processo ainda tímido de interiorização do crescimento, dada a enorme concentração populacional estadual na Região Metropolitana do Rio de Janeiro. Ressaltase, ainda, que essa interiorização é majoritariamente urbana.

Em virtude da crise econômica que vem afetando o país nos últimos anos e, no caso dos municípios do litoral Norte Fluminense, os produtores de petróleo, além da crise econômica provocada pela queda do preço do barril do petróleo no mercado internacional, é muito provável que o cenário aqui retratado tenha se alterado. No entanto, acredita-se que as alterações sejam de volume, e não de tendência. Em outras palavras, admite-se a redução dos poderes de atração e retenção e o aumento do poder de expulsão populacional por parte desses municípios, mas acredita-se que, mesmo diante desse cenário, os municípios do litoral Norte Fluminense permanecem como a principal frente de interiorização do Estado, o que só poderá ser confirmado com os resultados do próximo Censo Demográfico em 2020.

\section{Referências}

Baeninger, R. (1999). Migrações Internas no Brasil: municípios metropolitanos e não metropolitanos. In Anais do II Encontro Nacional sobre migração (pp. 535-562). Belo Horizonte: ABEP.

Brasil. (1973, 8 de junho). Lei Complementar n. 14, de 8 de junho de 1973. Estabelece as regiões metropolitanas de São Paulo, Belo Horizonte, Porto Alegre, Recife, Salvador, Curitiba, Belém e Fortaleza. Brasília: Diário Oficial da União. 
Brasil. (1974, 1 de julho). Lei Complementar n. 20, de $1^{\text {o }}$ de julho 1974. Dispõe sobre a criação de Estados e Territórios. Brasília: Diário Oficial da União.

Brito, F. (2002). Brasil, final do século: a transição para um novo padrão migratório? In: A. Carleial (Org.), Transições migratórias (pp. 54-72). Fortaleza. Iplance.

Brito, F., \& Souza, J. (2005). Expansão urbana nas grandes metrópoles o significado das migrações intrametropolitanas e da mobilidade pendular na reprodução da pobreza. São Paulo em Perspectiva, 19(4). 48-63.

Graham, D. H., \& Holanda, S. B. Fo. (1980). As migrações inter-regionais e urbanas e o crescimento econômico do Brasil. In H. Moura (Org.), Migração interna: textos selecionados (pp. 733-778). Fortaleza: Banco do Nordeste do Brasil, 2.

Instituto Brasileiro de Geografia e Estatística - IBGE. (1970). Censo Demográfico - 1970. Rio de Janeiro: IBGE. Recuperado em 14 de setembro de 2016, de www.ibge.gov.br

Instituto Brasileiro de Geografia e Estatística - IBGE. (1991). Censo Demográfico - 1991. Rio de Janeiro: IBGE. Recuperado em 14 de setembro de 2016, de www.ibge.gov.br

Instituto Brasileiro de Geografia e Estatística - IBGE. (2000). Censo Demográfico - 2000. Rio de Janeiro: IBGE. Recuperado em 14 de setembro de 2016, de www.ibge.gov.br

Instituto Brasileiro de Geografia e Estatística - IBGE. (2010). Censo Demográfico - 2010. Rio de Janeiro: IBGE. Recuperado em 14 de setembro de 2016, de www.ibge.gov.br

Lee, E. (1980). Uma teoria sobre migração. In H. Moura (Org.), Migração interna: textos selecionados (pp. 89-114). Fortaleza: Banco do Nordeste do Brasil.
Magalhães, J. C. (2007). Emancipação político-administrativa de municípios no Brasil. In A.X. Y. Carvalho, C. W. Albuquerque, J. A. Mota, M. Piancastelli (Orgs.), Dinâmica dos municípios (pp. 13-52). Brasília: IPEA.

Oliveira, A. T. R (2010). Tendências recentes da mobilidade espacial da população no Estado do Rio de Janeiro. Revista Brasileira de Estudos Populacionais, 27(1), 89-113.

Rigotti, J. I. R., \& Amorim, O. B. Fo. (2002). Aspectos demográficos do espaço mineiro. In: T. B. Guimarães, M. A. R. Cunha, M. Chaves, \& G. A. Prado (Orgs.), Minas Gerais do século XXI: reinterpretando o espaço mineiro (pp. 91-124). Belo Horizonte: Rona Editora.

Silva, R. D. (2012). A dinâmica econômica fluminense entre as décadas de 1930 e 1990. In: R. D. Silva, Indústria e desenvolvimento regional no Rio de Janeiro (parte I, cap. 1, pp. 41-66). Rio de Janeiro: Editora FGV.

Simões, R., Amaral, P. V (2011). Interiorização e novas centralidades urbanas: uma visão prospectiva para o Brasil. Economia, 12(3), 553-579.

Souza, J., \& Terra, D. (2015). Indústria petrolífera, mercado de trabalho e nível de dependência da mão de obra exógena nos municípios produtores de petróleo da Bacia de Campos, RJ. Revista Brasileira de Estudos Urbanos e Regionais, 17(1), 123-143. http://dx.doi. org/10.22296/2317-1529.2015v17n1p123.

Recebido: Set. 14, 2016

Aprovado: Fev. 23, 2017 